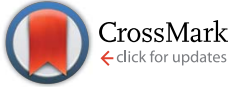

Cite this: RSC Adv., 2017, 7, 2231

Received 26th October 2016 Accepted 15th December 2016

DOI: $10.1039 / c 6 r a 25857 c$

www.rsc.org/advances

\title{
Readily switchable one-pot 5-exo-dig cyclization using a palladium catalyst $\uparrow$
}

\begin{abstract}
Jaishree K. Mali, Balaram S. Takale and Vikas. N. Telvekar*
A convenient, ligand-free, $\mathrm{Pd}(\mathrm{OAc})_{2}$-catalyzed one-pot reaction has been developed for the synthesis of oxazolines and oxazoles from easily available acid chlorides and propargylamine. The reaction pathways could be easily modulated to selectively obtain oxazolines or oxazoles by merely changing the additives. This method proceeds via in situ sequential nucleophilic addition/elimination reactions followed by an intramolecular 5-exo-dig cycloisomerization reaction. An interesting observation in this case is the effect of an additive: a basic additive such as triethylamine resulted in the formation of 5-methylene oxazolines, while an acidic additive such as acetic acid resulted in the formation of 5-methyloxazoles. With the current protocol we are able to obtain good to moderate yields of the desired product without the need for the isolation of intermediates.
\end{abstract}

\section{Introduction}

Oxazoles and oxazolines are ubiquitous heterocycles present in a variety of natural products, pharmaceuticals, agrochemicals, foods and polymers. ${ }^{1-4}$ Additionally, 2-oxazolines serve as synthetic intermediates, ${ }^{5}$ protecting groups in organic synthesis, and catalysts, ligands or auxiliaries in asymmetric synthesis. ${ }^{6,7}$

Several synthetic methods reported in the literature for substituted oxazole use Robinson-Gabriel synthesis cyclodehydration of 2-acylamino carbonyl compounds, ${ }^{\mathbf{8}}$ isomerisation of the oxazolines, ${ }^{9}$ base promoted reactions of primary aromatic amides and 2,3-dibromopropene, ${ }^{\mathbf{1 0}}$ catalytic decomposition of diazocarbonyl compounds in nitriles, ${ }^{\mathbf{1 1}}$ reductive desulfuration of 5 -methyl-4-methylthio-1,3-oxazoles, ${ }^{12}$ functionalisation (via metallation) of readily available oxazole $\mathrm{e}^{\mathbf{1 3}}$ and various condensation reactions. ${ }^{\mathbf{1 4}}$

Other straightforward methods for the synthesis of methylene oxazoline and oxazole include cycloisomerization of propargylamides. ${ }^{15}$ However, in this context cyclization of propargylamides to the corresponding oxazoles was achieved by strong base or strong acid using harsh conditions. ${ }^{\mathbf{1 6}}$

On the other hand, Lewis acids involving not only gold ${ }^{17}$ but also $\mathrm{ZnI}_{2}$ and $\mathrm{FeCl}_{3}{ }^{18}$ cerium chloride, ${ }^{19}$ ferric bromide, ${ }^{20}$ zinc triflate, ${ }^{21}$ Bronsted acid ${ }^{22}$ catalysts have emerged to afford oxazoles or oxazolines from corresponding propargylic amides. Besides these, metals such as silver, ${ }^{23}$ copper, ${ }^{24}$ palladium, ${ }^{25}$ mercury, ${ }^{26}$ ruthenium, ${ }^{27}$ tungsten and molybdenum ${ }^{28}$ have been explored. In fact, all of these strategies possess respective

Department of Pharmaceutical Sciences and Technology, Institute of Chemical Technology, Mumbai 400 019, India. E-mail: vikastelvekar@rediffmail.com

$\dagger$ Electronic supplementary information (ESI) available. See DOI: $10.1039 / \mathrm{c} 6 \mathrm{ra} 25857 \mathrm{c}$ drawbacks such as low yield, harsh reaction conditions, use of expensive ligands, and use of excess amount of additive or noncommercially available starting materials. Nevertheless, cycloisomerization of propargylamides to corresponding oxazole and oxazoline require synthesis, isolation and purification of propargylamides. Therefore, the development of single step protocol is highly desirable to minimize solvent waste and to maximize the yield of product. Taking this into consideration, TranDubéM et $a .^{29}$ explored one-pot synthesis of oxazoles from acid chlorides and propargylamines using gold-catalyst. Our curiosity was increased to replace expensive gold catalyst with well known palladium catalyst. ${ }^{30}$

Gratifyingly, we found an interesting result while performing optimization studies, use of basic additive selectively resulted in oxazoline, while use of acidic additive selectively resulted in oxazole. We believe, such kind of readily switchable protocol

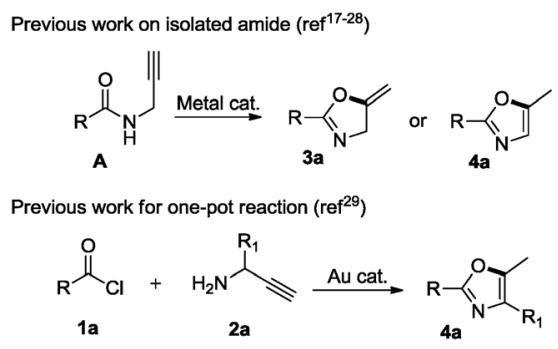

Current work for switchable one-pot reaction

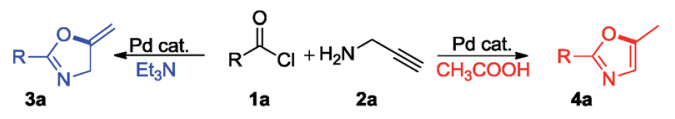

Scheme 1 Approach for the synthesis of dihydrooxazoles and oxazoles. 
which has wide applicability has not been explored previously (Scheme 1).

\section{Results and discussion}

We initiated the present study with benzoyl chloride and propargylamine as model substrates. Accordingly, propargylamine (2a, $1.82 \mathrm{mmol}$ ), benzoyl chloride (1a, $1.81 \mathrm{mmol})$, triethylamine (TEA) $(2.17 \mathrm{mmol})$ and $1 \mathrm{~mol} \%$ of $\mathrm{Pd}(\mathrm{OAc})_{2}$ were heated in toluene as a solvent, in a sealed tube at $100^{\circ} \mathrm{C}$ for $24 \mathrm{~h}$, oxazoline 3a was formed in $20 \%$ yield (Table 1 , entry 1 ). This results gave us a hint that $\mathrm{Pd}(\mathrm{OAc})_{2}$ is compatible with reaction conditions of one-pot synthesis. Further, we screened for the loading of $\mathrm{Pd}(\mathrm{OAc})_{2}$ from 2 to $10 \mathrm{~mol} \%$ (Table 1, entries 2-13). Remarkably, the desired product was obtained in $85 \%$ yield with $5 \mathrm{~mol} \%$ of the catalyst (Table 1 , entry 3 ). We also tried to replace TEA with inorganic or organic bases such as $\mathrm{K}_{2} \mathrm{CO}_{3}$ and diisopropylethylamine but resulted in $20 \%$ and $10 \%$ yield, respectively. In the absence of $\mathrm{Pd}(\mathrm{OAc})_{2}$ and TEA, no product was formed (Table 1 , entry 4). Only $\mathrm{Pd}(\mathrm{OAc})_{2}$ without any additive resulted in the trace amount of product $4 \mathbf{a}$ (confirmed by ${ }^{1} \mathrm{H}$ NMR) (Table 1 , entry 5 ). These blank reactions suggest that $\mathrm{Pd}(\mathrm{OAC})_{2}$ and TEA combination is crucial for selective formation of oxazoline $\mathbf{3 a}$.

A variety of solvents were tested for this reaction, from which no product was observed in DMF and DMSO. However, toluene gave the best result (Table 1, entries 3, 6-10). Remarkably, shortening of the reaction time from $24 \mathrm{~h}$ to $5 \mathrm{~h}$ resulted in the same yield of the desired product (Table 1, entries 11 and 12). Further, putting $10 \mathrm{~mol} \%$ of the catalyst with reaction time of $5 \mathrm{~h}$ did not show significant increment in the yield (Table 1, entry 13).
Surprisingly, we were able to obtain oxazole 4a exclusively when TEA was not used, although in very low amount (Table 1, entry 14). This strongly suggests that acidity is important for the formation of oxazole over oxazoline. To this end, a variety of acids including organic as well as inorganic solid acid catalysts were screened. Use of Amberlite IR 120-H, Amberlyst 15 (wet) and Montmorillonite led to the formation of the desired product in $15 \%, 30 \%$ and $50 \%$ yields respectively. Use of organic acids such as pivalic acid, trifluoroacetic acid and acetic acid resulted in $35 \%, 65 \%$ and $88 \%$ yield of the desired product, respectively. According to these results, an additive, TEA was replaced with $1.81 \mathrm{mmol}$ of acetic acid to give $88 \%$ yield of the desired product when the reaction was carried out with $5 \mathrm{~mol} \%$ of $\mathrm{Pd}(\mathrm{OAc})_{2}$ in toluene as a solvent at $100{ }^{\circ} \mathrm{C}$ for $24 \mathrm{~h}$ (Table 1 , entry 15$)$. Shortening of the time from $24 \mathrm{~h}$ to $12 \mathrm{~h}$ resulted in lower yield of the product (Table 1 , entry 16). It was observed that the reaction did not proceed towards the completion when less than 1 equivalents of TEA and acetic acid were used respectively, while their excess amount did not affect the yield of the desired product.

Finally, we had optimized conditions in hands, that is for oxazoline 3a; 1a $(1.82 \mathrm{mmol}), 2 \mathrm{a}(1.81 \mathrm{mmol}), 5 \mathrm{~mol} \%$ of $\mathrm{Pd}(\mathrm{OAc})_{2}$, TEA $(2.17 \mathrm{mmol})$ in toluene as solvent at $100{ }^{\circ} \mathrm{C}$ for $5 \mathrm{~h}$, and for oxazole $4 \mathrm{a} ; \mathbf{1 a}(1.82 \mathrm{mmol}), 2 \mathrm{a}(1.81 \mathrm{mmol}), 5 \mathrm{~mol} \%$ of $\mathrm{Pd}(\mathrm{OAc})_{2}$, acetic acid $(1.81 \mathrm{mmol})$ in toluene as solvent at $100{ }^{\circ} \mathrm{C}$ for $24 \mathrm{~h}$. Under these optimized reaction conditions, firstly we examined the scope of various acid chlorides for the synthesis of oxazolines (Table 2). Aroyl chlorides with either electron donating group on ortho-, meta- or para-position or electron withdrawing groups gave higher yields of the desired product (Table 2, entries 2-6).

Table 1 Optimization of the reaction conditions ${ }^{a}$

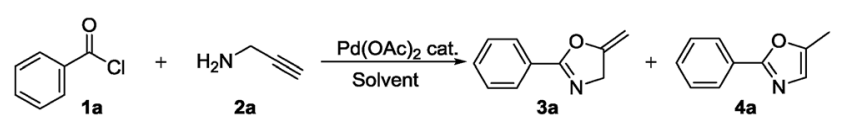

\begin{tabular}{|c|c|c|c|c|c|c|}
\hline Entry & Catalyst (mol\%) & Additive & Solvent & Temp $\left({ }^{\circ} \mathrm{C}\right) /$ time $(\mathrm{h})$ & $3 \mathbf{a}^{c}$ yield (\%) & $\mathbf{4 a}^{c}$ yield (\%) \\
\hline 1 & 1 & TEA & Toluene & $100 / 24$ & 20 & 0 \\
\hline 2 & 2 & TEA & Toluene & $100 / 24$ & 45 & 0 \\
\hline 4 & - & - & Toluene & $100 / 24$ & 0 & 0 \\
\hline 5 & 1 & - & Toluene & $100 / 24$ & 0 & $<2 \%^{b}$ \\
\hline 6 & 5 & TEA & $\mathrm{CH}_{2} \mathrm{Cl}_{2}$ & $40 / 24$ & 30 & 0 \\
\hline 9 & 5 & TEA & THF & $65 / 24$ & 32 & 0 \\
\hline 10 & 5 & TEA & 1,4-Dioxane & $100 / 24$ & 35 & 0 \\
\hline 11 & 5 & TEA & Toluene & $100 / 12$ & 85 & 0 \\
\hline 12 & 5 & TEA & Toluene & $100 / 5$ & 85 & 0 \\
\hline 13 & 10 & TEA & Toluene & $100 / 5$ & 88 & 0 \\
\hline 14 & 5 & - & Toluene & $100 / 24$ & 0 & 25 \\
\hline
\end{tabular}

${ }^{a}$ Reaction conditions: acid chloride $(1.82 \mathrm{mmol})$, propargylamine $(1.81 \mathrm{mmol})$, catalyst $\mathrm{Pd}(\mathrm{OAc})_{2}(\mathrm{~mol} \%)$, additive TEA (triethylamine) $2.17 \mathrm{mmol}$ or acetic acid $1.81 \mathrm{mmol}$ in $2 \mathrm{~mL}$ of dry solvent in a sealed tube. ${ }^{b}$ Detected by ${ }^{1} \mathrm{H}$ NMR. ${ }^{c}$ Isolated yield. 
Table 2 One pot synthesis of oxazolines ${ }^{a}$

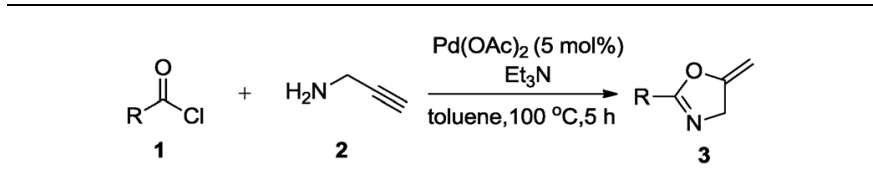

\begin{tabular}{|c|c|c|c|}
\hline Entry & Acid chlorides; 1 & Product; 3 & Yield of $3^{b}(\%)$ \\
\hline
\end{tabular}

1<smiles>O=C(Cl)c1ccccc1</smiles><smiles>C=C1CN=C(c2cc[14cH][14cH][14cH]2)O1</smiles>

85

2<smiles>Cc1ccc(C(=O)Cl)cc1</smiles><smiles>C=C1CN=C(c2ccc([125I])cc2)O1</smiles>

85

3<smiles>Cc1cccc(C(=O)Cl)c1</smiles><smiles>C=C1CN=C(c2ccc(C)cc2)O1</smiles>

70

4<smiles>O=C(Cl)c1ccc(F)cc1</smiles><smiles>C=C1CN=C(c2ccc(F)cc2)O1</smiles>

92

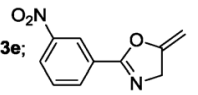

84

3f;<smiles>C=C1CN=C(c2ccccc2Br)O1</smiles><smiles>O=C(Cl)c1ccccc1Br</smiles><smiles>O=C(Cl)c1cc(Cl)cc(Cl)c1</smiles><smiles>C=C1CN=C(c2cc(Cl)cc(Cl)c2)O1</smiles>

82

3h;<smiles>O=C(Cl)/C=C/c1ccccc1</smiles><smiles>[13CH3][14C](=O)Cl</smiles><smiles></smiles>

45
Table 3 One pot synthesis of oxazoles ${ }^{a}$

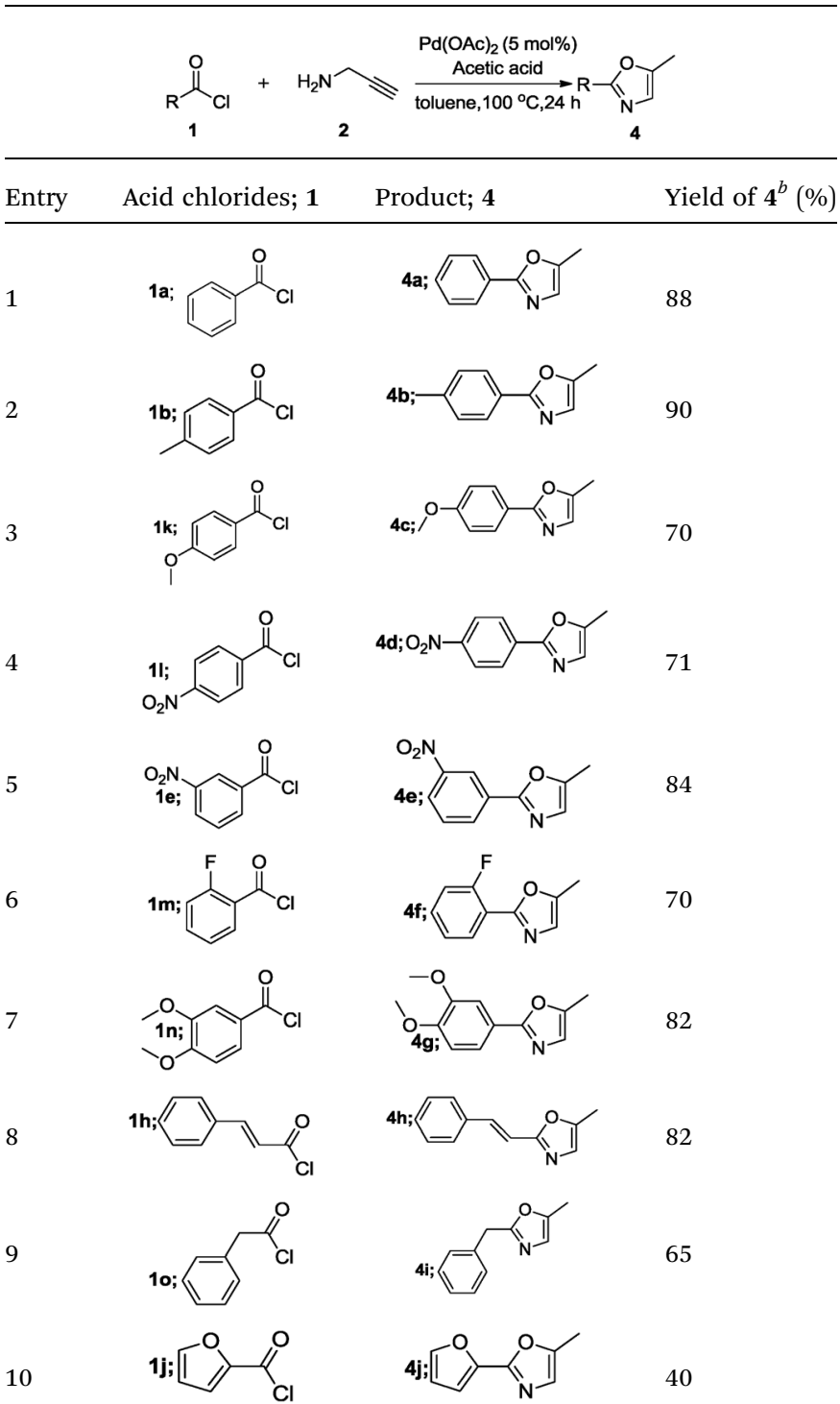

${ }^{a}$ Reaction conditions: acid chloride $(1.82 \mathrm{mmol})$, propargylamine (1.81 $\mathrm{mmol})$, catalyst $\mathrm{Pd}(\mathrm{OAc})_{2}(5 \mathrm{~mol} \%)$, TEA (triethylamine) $2.17 \mathrm{mmol}$ in 2 $\mathrm{mL}$ of dry toluene in a sealed tube at $100{ }^{\circ} \mathrm{C}$ for $5 \mathrm{~h}$. ${ }^{b}$ Isolated yield.

Aliphatic derivatives also furnished the desired product in moderate to good yield (Table 2, entries 8 and 9). Heterocyclic derivatives gave slightly lower yield (Table 2, entry 10). Noteworthy to mention, multiple substituent on the ring were also tolerated (Table 2, entry 7).

Secondly, using optimized reaction conditions available for oxazoles, we investigated the scope for variety of substrate (Table 3). Mono- and disubstituted aroyl chlorides were easily transformed to give good yields of the desired products (Table 3, entries 2-7). Both electron donating and electron withdrawing substrates were readily converted into the desired products (Table 3, entries 2-7). Furthermore, substituents at different positions on the aryl group (para-, meta-, ortho-positions), did not affect the reaction efficiency (Table 3, entries 2-6). Heteroaryl derivatives gave lower yield (Table 3 , entry 10). Aliphatic

\begin{abstract}
${ }^{a}$ Reaction conditions: acid chloride $(1.82 \mathrm{mmol})$, propargylamine (1.81 $\mathrm{mmol})$, catalyst $\mathrm{Pd}(\mathrm{OAc})_{2}(5 \mathrm{~mol} \%)$, acetic acid $1.81 \mathrm{mmol}$ in $2 \mathrm{~mL}$ of dry toluene in a sealed tube at $100{ }^{\circ} \mathrm{C}$ for $24 \mathrm{~h} .{ }^{b}$ Isolated yield.
\end{abstract}

acid chlorides also gave the desired products in good to moderate yields (Table 3, entries 8 and 9).

After this successful study, we performed one control experiment to check effect of atmospheric oxygen on the reaction (Scheme 2). It is reported in the literature ${ }^{25 b}$ that metalvinylidene formed as an intermediate could be easily converted to aldehyde 5a. However, in our reaction condition we

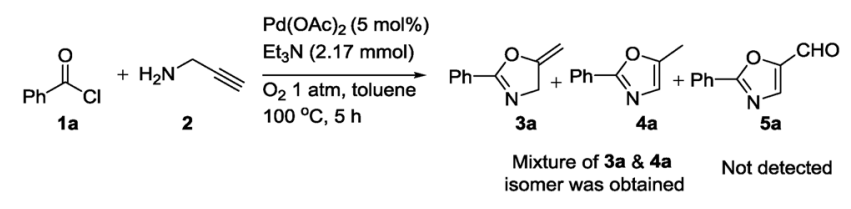

Scheme 2 Control experiments. 

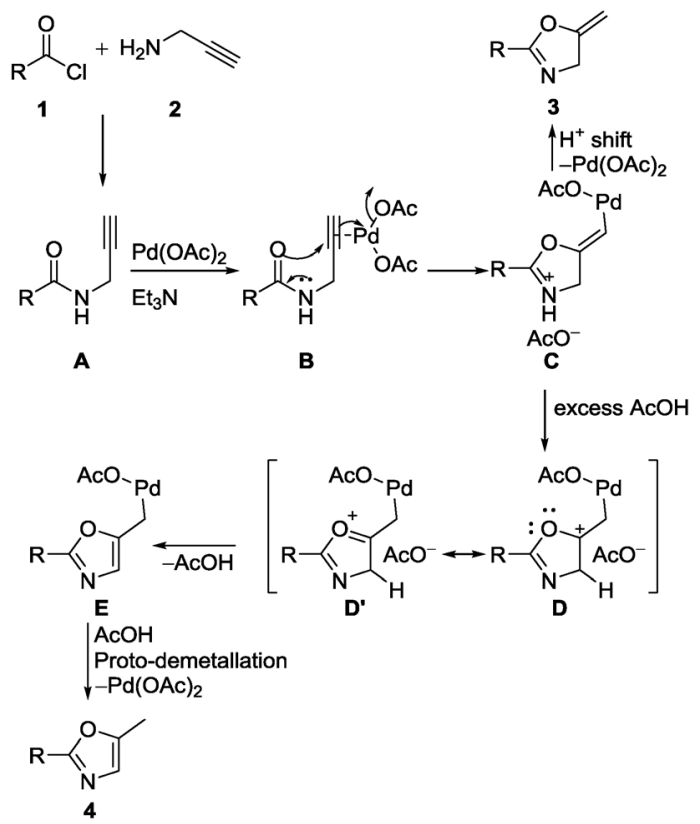

Scheme 3 Plausible reaction mechanism.

were not able to obtain such oxidized product 5a, and rather mixture of 3a and $\mathbf{4 a}$ could be obtained. It was noted that in the case of synthesis of oxazolines, small quantities of inactive palladium black were observed in the solution after the completion of reaction. On the other hand, in case of oxazoles, no formation of palladium black was observed. It could be hypothesized that acetic acid significantly helped in the regeneration of palladium acetate. In addition, to extend the scope of our methodology, we carried out reaction using secondary amine such as $N$-methylpropargylamine, but unidentified mixture of products was isolated.

Based on the literature and experimental details, we proposed a plausible reaction pathway (Scheme 3). The reaction proceeds via in situ formation of propargylamide by nucleophilic addition/elimination reactions of acid chlorides and propargylamine. Palladium acetate coordinates to the carboncarbon triple bond of in situ formed propargylamide $\mathbf{A}$ to form organo-palladium species $\mathbf{B}$ followed by triethylamine assisted intramolecular nucleophilic attack of enolate on alkyne to produce vinyl palladium $\mathbf{C}$ in 5-exo-dig manner. Intermediate $\mathbf{C}$ can either undergo proto-demetallation to give oxazoline 3 or it can undergo aromatization in the presence of excess of acetic acid to give oxazole 4 . The path towards the formation of 4 includes initial protonation of double bond of vinyl palladium complex $\mathbf{C}$ to give $\mathbf{D}$, (this complex is in resonance with complex $\mathbf{D}^{\prime}$ ) which undergoes aromatization by losing neighboring proton to form $\mathbf{E}$ before giving the final product 4 by proto-demetallation.

\section{Conclusions}

In conclusion, we have developed one pot synthesis of 2-oxazolines and 2-oxazoles, catalyzed by palladium acetate via sequential nucleophilic addition/elimination reactions followed by intramolecular cycloisomerization reaction via 5-exodig mode. Moreover, the reaction pathway could be easily tuned by merely changing additives such as triethylamine or acetic acid to exclusively furnish 2-oxazolines or 2-oxazoles respectively. These protocols exhibit tolerance towards wide range of substrates to afford the desired product in moderate to good yield, except heteroaromatics, which furnished both the product oxazolines and oxazoles in slightly lower yield. Aliphatic acid chlorides also offered exclusively oxazolines and oxazoles in good yield without formation of complex mixture of the isomerised product. Being one-pot these reactions offer high step economy and does not require solvent exchanges or isolation of intermediates. In future, manipulation at the 5methylene position of oxazolines could provide an avenue to wide variety of functionalized oxazoles. This protocol circumvents the use of expensive ligands. Synthetic application of the present work is underway in our laboratory.

\section{Acknowledgements}

The author JKM is greatly thankful to the UGC (University Grant Commissions), New Delhi, India for providing a Basic Science Research (BSR) fellowship and VNT thanks the Science and Engineering Research Board (SERB), New Delhi, India, for providing financial support.

\section{References and notes}

1 (a) Z. Jin, Nat. Prod. Rep., 2011, 28, 1143-1191; (b) M. Tsuda, M. Yamakawa, S. Oka, Y. Tanaka, Y. Hoshino, Y. Mikami, A. Sato, H. Fujiwara, Y. Ohizumi and J. Kobayashi, J. Nat. Prod., 2005, 68, 462-464; (c) L. J. Perez, D. J. Faulkner and W. Fenical, J. Nat. Prod., 2003, 66, 247-250; (d) Z. Jin, Nat. Prod. Rep., 2013, 30, 869-915; (e) P. Wipf, Chem. Rev., 1995, 2115-2134; (f) Z. Jin, Nat. Prod. Rep., 2006, 23, 464-496; $(g)$ R. N. Misra, H. Xiao, K. S. Kim, S. Lu, W. Han, S. A. Barbosa, J. T. Hunt, D. B. Rawlins, W. Shan, S. Z. Ahmed, L. Qian, B. Chen, R. Zhao, M. S. Bednarz, K. A. Kellar, J. G. Mulheron, R. Batorsky, U. Roongta, A. Kamath, P. Marathe, S. A. Ranadive, J. S. Sack, J. S. Tokarski, N. P. Pavletich, F. Y. F. Lee, K. R. Webster and S. D. Kimball, J. Med. Chem., 2004, 47, 1719-1728.

2 (a) D. C. Palmer and S. Venkatraman, The Chemistry of Heterocyclic Compounds, A Series of Monographs, Oxazoles: Synthesis, Reactions, and Spectroscopy, Part A, ed. D. C. Palmer, John Wiley \& Sons, NJ, 2003, vol. 60; (b) Oxazoles: Synthesis, Reactions and Spectroscopy, Part B, ed. D. C. Palmer, John Wiley \& Sons, Hoboken, NJ, 2004; (c) Y. Kato, N. Fusetani, S. Matsunaga, K. Hashimoto, K. S. Fujita and T. Furuya, J. Am. Chem. Soc., 1986, 108, 2780-2781; (d) G. Pattenden, J. Heterocycl. Chem., 1992, 29, 607.

3 (a) J. A. Frump, Chem. Rev., 1971, 71, 483; (b) J. A. Maga, J. Agric. Food Chem., 1978, 26, 1049-1050.

4 R. Hoogenboom, Angew. Chem., Int. Ed., 2009, 48, 7978-7994.

5 H. H. Wasserman, K. E. Mccarthy and K. S. Prowse, Chem. Rev., 1986, 86, 845-856. 
6 H. Vorbrüggen and K. Krolikiewicz, Tetrahedron, 1993, 49, 9353-9372.

7 (a) A. Gissibl, M. G. Finn and O. Reiser, Org. Lett., 2005, 7, 2325-2328; (b) H. Nlshiyama, H. Sakaguchi, T. Nakamura, M. Horlhata, M. Kondo and K. Itoh, Organometallics, 1989, 8, 846-848; (c) H. A. Mcmanus and P. J. Guiry, Chem. Rev., 2004, 104, 4151-4202; (d) G. C. Hargaden and P. J. Guiry, Chem. Rev., 2009, 109, 2505-2550.

8 H. H. Wasserman and F. J. Vinick, J. Org. Chem., 1973, 38, 2407-2408.

9 R. Lakhan and B. Ternai, Adv. Heterocycl. Chem., 1974, 17, 99.

10 N. Yasmin and J. K. Ray, Synlett, 2009, 2825-2827.

11 M. P. Doyle, W. E. Buhro, J. G. Davidson, R. C. Elliott, J. W. Hoekstra and M. Oppenhuizenlc, J. Org. Chem., 1980, 45, 3657-3664.

12 A. Herrera, R. Martinez-Alvarez, P. Ramiro, D. Molero and J. Almy, J. Org. Chem., 2006, 71, 3026-3032.

13 C. Kashima and H. Arao, Synthesis, 1989, 873-874.

14 (a) I. J. Turchi and M. J. S. Dewar, Chem. Rev., 1975, 75, 389432; (b) B. H. Lipshutz, Chem. Rev., 1986, 86, 795-819; (c) R. H. Wiley and L. L. Bennett, Chem. Rev., 1949, 44, 447476; (d) C. T. Brain and J. M. Paul, Synlett, 1999, 1642-1644. 15 Y. Hu, X. Xin and B. Wan, Tetrahedron Lett., 2015, 56, 32-52. 16 (a) B. M. Nilsson, H. M. Vargas, B. Ringdahl and U. Hacksell, J. Med. Chem., 1992, 35, 285-294; (b) P. Wipf, L. T. Rahman and S. R. Rector, J. Org. Chem., 1998, 63, 7132-7133; (c) B. D. Conny Bogentoft, Ö. Ericsson and P. Stenberg, Tetrahedron Lett., 1969, 10, 4745-4748; (d) H. Araki, T. Katoh and M. Inoue, Synlett, 2006, 555-558; (e) K. E. Schulte, J. Reisch and M. Sommer, Arch. Pharm., 1966, 299, 107-112.

17 (a) S. K. Hashmi, J. P. Weyrauch, W. Frey and J. W. Bats, Org. Lett., 2004, 6, 4391-4394; (b) J. P. Weyrauch, A. S. K. Hashmi, A. Schuster, T. Hengst, S. Schetter, A. Littmann, M. Rudolph, M. Hamzic, J. Visus, F. Rominger, W. Frey and J. W. Bats, Chem. - Eur. J., 2010, 16, 956-963; (c) A. S. K. Hashmi, M. C. Blanco Jaimes, A. M. Schuster and F. Rominger, J. Org. Chem., 2012, 77, 6394-6408; (d) O. A. Egorova, H. Seo, Y. Kim, D. Moon, Y. M. Rhee and K. H. Ahn, Angew. Chem., Int. Ed., 2011, 50, 11446-11450; (e) H. Peng, N. G. Akhmedov, Y. F. Liang, N. Jiao and X. Shi, J. Am. Chem. Soc., 2015, 137, 8912-8915; (f) D. Aguilar, M. Contel, R. Navarro, T. Soler and E. P. Urriolabeitia, J. Organomet. Chem., 2009, 694, 486-493; (g) A. S. K. Hashmi, A. M. Schuster and F. Rominger, Angew. Chem., Int. Ed., 2009, 48, 8247-8249; (h) A. S. K. Hashmi, A. M. Schuster, M. Schmuck and F. Rominger, Eur. J. Org. Chem., 2011,
4595-4602; ( $i$ ) C. L. Paradise, P. R. Sarkar, M. Razzak and J. K. De Brabander, Org. Biomol. Chem., 2011, 9, 4017.

18 G. C. Senadi, W. Hu and J. J. Wang, Org. Lett., 2013, 14, 44784481.

19 G. Bartoli, C. Cimarelli, R. Cipolletti, S. Diomedi, R. Giovannini, M. Mari, L. Marsili and E. Marcantoni, Eur. J. Org. Chem., 2012, 630-636.

20 X.-H. Gao, P.-C. Qian, X.-G. Zhang and C.-L. Deng, Synlett, 2016, 27, 1110-1115.

21 B. Wang, Y. Chen, L. Zhou, J. Wang, C. H. Tung and Z. Xu, J. Org. Chem., 2015, 80, 12718-12724.

22 E. Merkul and T. J. J. Muller, Chem. Commun., 2006, 48174819.

23 (a) M. Harmata and C. Huang, Synlett, 2008, 1399-1401; (b) V. H. L. Wong, A. J. P. White, T. S. Hor and K. K. Hii, Adv. Synth. Catal., 2015, 357, 3943-3948.

24 (a) J. Chunyang, J. P. Burgess, J. A. Kepler and C. E. Cook, Org. Lett., 2007, 9, 1887-1890; (b) A. Alhalib and W. J. Moran, Org. Biomol. Chem., 2014, 12, 795-800.

25 (a) A. Saito, K. Iimura and Y. Hanzawa, Tetrahedron Lett., 2010, 51, 1471-1474; (b) E. M. Beccalli, E. Borsini, G. Broggini, G. Palmisano, S. Sottocornola, C. Organica, V. Uni and V. Uni, J. Org. Chem., 2008, 73, 4746-4749; (c) A. Bacchi, M. Costa, B. Gabriele, G. Pelizzi and G. Salerno, J. Org. Chem., 2002, 67, 4450-4457; (d) A. Arcadi, S. Cacchi, L. Cascia, G. Fabrizi, F. Marinelli, D. L. Aquila, V. Vetoio, C. Due and I.-L. Aquila, Org. Lett., 2001, 3, 2501-2504; (e) A. Bacchi, M. Costa, N. Della Cà, B. Gabriele, G. Salerno and S. Cassoni, J. Org. Chem., 2005, 70, 4971-4979; (f) A. Saito, K. Iimura and Y. Hanzawa, Tetrahedron Lett., 2010, 51, 1471-1474.

26 L. J. Street, J. R. Baker, J. L. Castro, M. S. Chambers, A. R. Guiblin, S. C. Hobbs, V. G. Matassa, A. J. Reeve, M. S. Beer, D. N. Middlemiss, A. J. Noble, J. A. Stanton, K. Scholey and R. J. Hargreaves, J. Med. Chem., 1993, 36, 1529-1538.

27 M. D. Milton, Y. Inada, Y. Nishibayashi and S. Uemura, Chem. Commun., 2004, 2712-2713.

28 X. Meng and S. Kim, Org. Biomol. Chem., 2011, 9, 4429-4431. 29 M. Tran-Dubé, S. Johnson and I. McAlpine, Tetrahedron Lett., 2013, 54, 259-261.

30 (a) V. Michelet, P. Y. Toullec and J. P. Genêt, Angew. Chem., Int. Ed., 2008, 47, 4268-4315; (b) G. Zeni and R. C. Larock, Chem. Rev., 2004, 104, 2285-2309; (c) I. Nakamura and Y. Yamamoto, Chem. Rev., 2004, 104, 2127-2198; (d) R. Chinchilla and C. Nájera, Chem. Rev., 2014, 114, 17831826; (e) G. Zeni and R. C. Larock, Chem. Rev., 2007, 107, 303. 